\title{
TO STUDY THE IMPACT OF MTWP IN GRIP STRENGTH AMONG PEOPLE WITH WRIST INJURIES.
}

\author{
Dr.SurendraKumar Meena ${ }^{1}$ Dr.Neha Jain ${ }^{2}$ \\ ${ }^{1}$ Principal, Mahatma Gandhi Occupational Therapy College \\ Director, Paramedical Studies, Mahatma Gandhi University of Medical Sciences \& Technology, \\ Jaipur. \\ Director, SNM Rehabilitation \& Autism Research Institute, Jaipur \\ ${ }^{2}$ Assistant Professor, Mahatma Gandhi Occupational Therapy College, Jaipur \\ Corresponding email: id -skmeena@,rediffmail.com
}

\begin{abstract}
Introduction and aim: Wrist injuries by colles' or fracture of distal radius are the most prominent diagnosis referred to occupational therapy department for work program in India. In this project, a modified therapeutic work program for wrist injuries was evaluated. The objective of the study is to find out whether MTWP addressed to enhance the grip strength so as work skills and its success in the client return to work, level of work satisfaction \& self-performance level post injured wrist.

Methods: Single group pretest posttest experimental design followed by descriptive analysis.51 patients with dominant hand injured, shared similar demographic background with post-injured from 8 to 40 weeks with mean age of 16 weeks.

Results: $94 \%$ clients who completed the program returned to work and switched over to different position and different type of work. $56 \%$ clients return to competitive employment with same work type, work situation, having work satisfaction and 80-100\% work skills in compare to pre MTWP work situation.

Discussion: The MTWP addresses the range of needs demonstrated by wrist injuries clients, from traditional therapy to prevocational and vocational intervention. The evaluation of the program indicates that the program was successful with wrist injury working age adult.
\end{abstract}

Key words: MTWP, colles fracture, vocation, wrist injuries, grip strength

\section{INTRODUCTION}

The importance of hand in human culture and functional activities has long been recognized. Wrist is structured to provide a stable base to allow hand to conduct complex motion, and is the major joint responsible for work tasks. In India, wrist injuries are the therapy department for work program. In this project, a modified therapeutic work program for wrist injuries was evaluated.

Colles' fracture is defined as a linear transverse fracture of the distal radius approximately $20-35 \mathrm{~mm}$ proximal to the articular surface with dorsal angulations' of the distal fragment( 1).The unstable 
fractures are distinctly comminuted often with corresponding avulsions of the ulnar or radial styloid that have the potential to cause compression neuropathies, especially of the median nerve (1).The other complications that have been reported include reflex sympathetic dystrophy and degenerative joint disease (1).

As the life expectancy continues to increase with increase in industrialization in country like India, the frequency of fractures to the wrist can be expected to increase in years to come. The patients with distal radial fracture are off work from 67days upto 20 weeks $(8,9)$.It is for this reason that post traumatic occupational therapy is critical in restoring function and has a direct influence on the quality of life, as well as duration of sick leave, laborer compensation and therefore is of social economic interest.

The current study is primarily based on the concept of TWP. However it is intended for use on the individual with wrist injury in combination with traditional therapies. Literature search failed to reveal similar studies in Indian context.

\section{Material and Methods:}

DESIGN- Single group pretest posttest experimental design followed by descriptive analysis.A different subject prospective, experimental, flexible design has been used for the purpose of this study. MTWP has 6 phases with treatment plan based on client capabilities, deficits, interest, work history and goals.

SUBJECTS-A total number of 51 subjects having wrist injuries by colles'or fracture distal radius of dominant hand were selected for the study. Mean age was 36 years (range 25 to 55 years) having both male and female. The post injury duration for participation in MTWP is 08 to 40 weeks, mean 16 weeks (Table 1). Period of study from April 09 to Aug 10. Clients were explained the purpose of the study and were requested to participate in the study. Written consent obtained from each participant before study begins.

Instrumentation:

- Minnesota Manual Dexterity Test(MMDT)

- Hand Dynamometer \& Pinch meter

- Short Form-36(version 1) - subjective outcome assessment for functional/ work status.

HAND DYNAMOMETER-The Hydraulic Jamar grip dynamometer( Figure 2a) with five adjustable handle spacing provides an accurate evaluation of the force of grip .Developed by Bechtol C. (1954) and recommended by professional societies, 
the Jamer dynamometer has been shown to be a reliable test instrument, provided calibration is maintained and standard positioning of test subject is followed. This dynamometer has five adjustable spacing at $1,1.5,2,2.5$ and 3 inches. The client is shown how to grasp the dynamometer and is requested to grasp it with his or her maximal force. The grip test position should be standardized. The forearm should be in neutral rotation and the elbow flexed 90 degree. The shoulder should be adducted .The wrist should be between 0 and 30 degree of extension and 0 and 15 degree of ulnar deviation .The grip can measure at each of the five-handle spacing. The right and left hands are tested alternately and the force of each is recorded. The test is placed at a rate to eliminate fatigue. There are 30 brands new dynamometer available in the market and $80 \%$ met the correlation criterion of + 0.9994. In 1978 and 1983, the ASSH recommended that the second handle position be used and average of 3-trials be recoded.

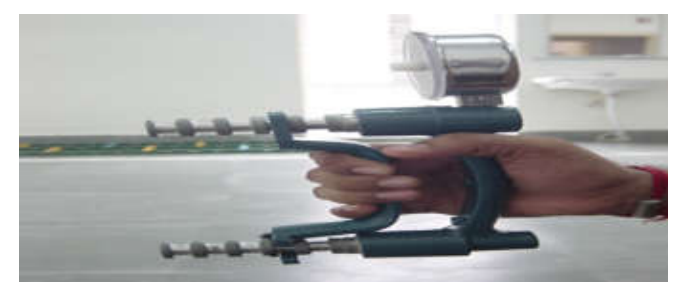

\section{MODIFIED THERAPEUTIC WORK PROGRAMME}

MTWP Six Phases:

Phase 1- Individual assessment and treatment in occupational therapy department.

Individualized assessment by occupational therapist were obtained from Initial general occupational therapy assessment format, which includes-

-Date of injury, participation in MTWP

-About previous job specification / demand which based on information from Canadian Classification and Dictionary of Occupations.

-Obtaining background information pertinent to work.

-FIM for ADL.

Phase 2- Group treatment.

-In this phase as client progress to higher level of functioning they participate in group treatment.

-Groups are led by occupational therapist.

-Emphasis is on interaction and interpersonal skills.

-Groups are functionally based and focus on area such as functional living skills, debate and effective communication and family education.

Phase 3 - Prevocational assessment. 
The first two sessions are devoted to a prevocational assessment. These assessments establish a baseline performance level and guides appropriate task selection.

-The outcome measure as mentioned earlier is used here.

-It guides appropriate secretarial task, and assembling task to be chosen as per the need of an individual client.

Phase 4 - Therapeutic work groups.

-All Initial transition from role of client to the role of worker.

-Client received 5 days per week for $1($ One) hour daily for 4 weeks.

-The group structure includes sign an attendance register in and out, a daily routine, involved in variety of assembly tasks (Figure 4) and secretarial task (Figure $5)$.

-Emphasis is on developing prevocational and work readiness skills, not on training for specific job.

Phase 5 - Work placement within the institute.

-Supervised work placements within the institute are available on block printing, appliqué \& computer programming.
-If only client show interest to participate then posted under vocational counselor for further guidance and training.

Phase 6 - Back to previous job or supervised placement in community or further education and training.

-Previously employed client go back to their respective job.

-Supervised placement in community

-Clients engage in further education and training.

\section{RESULT \& DISCUSSION}

Table 1 (Demographic Details of patients participated in MTWP)

\begin{tabular}{|l|l|l|}
\hline Sl.No. & Characteristic & Groups \\
\hline $\mathbf{0 1}$ & No. of Subjects & $\mathbf{5 1}$ \\
\hline $\mathbf{0 2}$ & Age range & $\mathbf{2 5 - 5 5}$ yrs. \\
\hline $\mathbf{0 3}$ & Mean age & $\mathbf{3 6}$ \\
\hline $\mathbf{0 4}$ & Male/Female & $\mathbf{2 1 / 3 0}$ \\
\hline $\mathbf{0 5}$ & $\begin{array}{l}\text { Dominant hand } \\
\text { injured Rt./ Lt. }\end{array}$ & $\mathbf{4 6 / 0 5}$ \\
\hline $\mathbf{0 6}$ & $\begin{array}{l}\text { Post injury } \\
\text { duration }\end{array}$ & $\begin{array}{l}\mathbf{0 8} \text { to 40 } \\
\text { weeks, } \\
\text { mean } \quad \text { 16 } \\
\text { weeks }\end{array}$ \\
\hline
\end{tabular}

Table - 2 Work status comparison of Pre MTWP and Post MTWP Subjects (N 48) 


\begin{tabular}{|l|l|l|}
\hline Work Status & $\begin{array}{l}\text { Pre } \\
\text { morbid }\end{array}$ & $\begin{array}{l}\text { Post } \\
\text { MTWP }\end{array}$ \\
\hline $\begin{array}{l}\text { Competitive } \\
\text { employment }\end{array}$ & 33 & $\mathbf{3 1}$ \\
\hline Homemaker & 15 & $\mathbf{1 4}$ \\
\hline Trainee & 00 & $\mathbf{0 1}$ \\
\hline Unemployed & $\mathbf{0 0}$ & $\mathbf{0 2}$ \\
\hline
\end{tabular}

4) shows, the categories of work vary from those prior to the wrist injuries. The clients did work that was different from the work they had done prior to the wrist injuries.

Table - 4 Work situation comparison preceding and following Wrist injury (N46)

As table-2 shows, out of 48 clients in premorbid stage, 45 clients were working after participating in the MTWP (31 were competitively employed, 14 primary homemaker) whereas 1 trainee and 2 were unemployed.

Table -3 Work type comparison of Premorbid (N- 48) and Post MTWP (N46) Subjects

\begin{tabular}{|l|l|l|}
\hline Work Type & Premorbid & $\begin{array}{l}\text { Post- } \\
\text { MTWP }\end{array}$ \\
\hline Managerial & 12 & $\mathbf{1 3}$ \\
\hline Heavy labor & 03 & $\mathbf{0 1}$ \\
\hline $\begin{array}{l}\text { Light Labor } \\
\text { (Secretarial \& } \\
\text { assembling) }\end{array}$ & 18 & $\mathbf{1 6}$ \\
\hline Student & 00 & $\mathbf{0 1}$ \\
\hline Home maker & 15 & $\mathbf{1 4}$ \\
\hline Others & $\mathbf{0 0}$ & $\mathbf{0 1}$ \\
\hline
\end{tabular}

The work type comparison (eg. managerial, heavy labor, light labor, home maker) of premorbid and post MTWP subjects (Table-

\begin{tabular}{|c|c|c|}
\hline \multicolumn{2}{|l|}{ Work Situation } & $\begin{array}{l}\text { Number of } \\
\text { subjects }(N-46)\end{array}$ \\
\hline \multicolumn{2}{|c|}{$\begin{array}{l}\text { Same company / Same } \\
\text { position }\end{array}$} & 39(14)a \\
\hline \multicolumn{2}{|c|}{$\begin{array}{l}\text { Same company/ other } \\
\text { position }\end{array}$} & 04 \\
\hline \multicolumn{2}{|c|}{$\begin{array}{l}\text { Other company/same } \\
\text { work type }\end{array}$} & 02 \\
\hline \multicolumn{2}{|c|}{$\begin{array}{l}\text { Other company/other } \\
\text { work type }\end{array}$} & 01(1)b \\
\hline \multicolumn{3}{|c|}{ 'a' for home maker and ' $b$ ' for student } \\
\hline \multirow{2}{*}{\multicolumn{3}{|c|}{$\begin{array}{l}\text { Table- } 5 \text { shows, the comparison of present } \\
\text { job with former job. Return to the same or a } \\
\text { different company was related to the length } \\
\text { of time of prior employment. } \\
\text { Table }-5 \text { Number of jobs held by subjects } \\
\text { since discharge }(\mathbf{N}-\mathbf{4 6})\end{array}$}} \\
\hline & & \\
\hline Number of jobs & \multicolumn{2}{|c|}{ Number of Subjects } \\
\hline 1 & \multicolumn{2}{|l|}{37} \\
\hline 2 & \multicolumn{2}{|l|}{05} \\
\hline 3\& more & \multicolumn{2}{|l|}{$\mathbf{0 3}$} \\
\hline NR & \multicolumn{2}{|l|}{01} \\
\hline
\end{tabular}

'NR' - Not Report 
Table-5 shows, 37 out of 46 subjects had one jobs, 05 had two jobs, 03 had three or more jobs since discharge from MTWP. The majority of respondent, 44 out of 46 were working 40 or more hours per week.

As per job satisfaction level out of 46 subjects; 32 liked their job, 05 did not enjoy their work, 03 home makers want to be involved in competitive employment and 05 subjects feel the job is challenging and look forward to it.

TABLE -6

SUBJECTIVE WORK DIFFICULTY (N - 46)

\begin{tabular}{|l|l|}
\hline Job required more physical demand & $\mathbf{0 8}$ \\
\hline Job required high cognitive demand & $\mathbf{0 3}$ \\
\hline $\begin{array}{l}\text { Easiest job that repetitious, familiar } \\
\text { \& required few cognitive \& physical } \\
\text { demand }\end{array}$ & 35 \\
\hline
\end{tabular}

Post MTWP in the area of work difficulty, 35 subjects suggest the job that repetitious, familiar, required little cognitive \& physical demand is easy to perform (Table 8). In comparing their present work skills with their skills prior to affection 27 subjects self reported 100 to $80 \%$ of their prior level in job performance (Table 9).
Table -7 Self-evaluation of job

performance

\begin{tabular}{|l|l|l|l|l|l|}
\hline GROUP & Mean & SD & SE & T & P \\
Mean & & \\
\hline $\begin{array}{l}\text { Grip } \\
\text { strength } \\
\text { Injured } \\
\text { side( }\end{array}$ & -3.60 & 2.48 & 0.44 & - & 0.01 \\
AFFG1- & & & & 6.92 & \\
AFFG2) & & & & & \\
\hline $\begin{array}{l}\text { Grip } \\
\text { strength } \\
\text { Non- } \\
\text { injured } \\
\text { side( }\end{array}$ & -0.62 & 0.52 & 0.14 & - & 0.01 \\
NAG1- & & & 4.09 & \\
NAG2) & & & & & \\
Table showingmean Grip strength \\
injured side in compare to mean Grip \\
strength Non-injured before and after 4 \\
weeks during MTWP. & & & \\
\hline
\end{tabular}

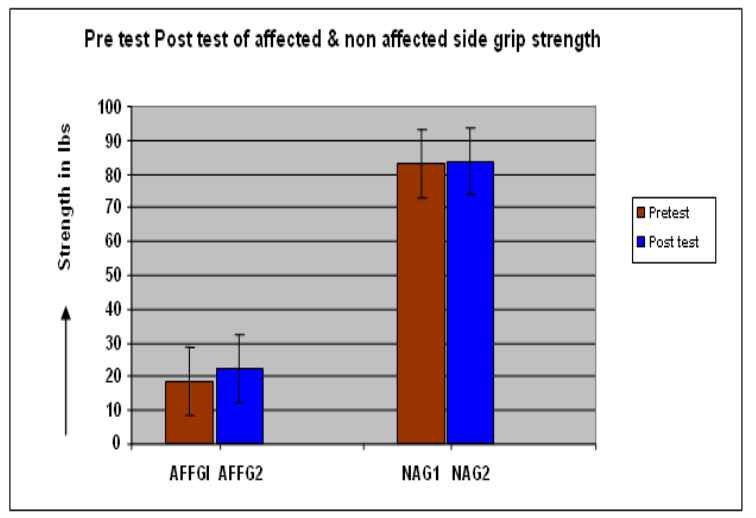


Graph 1 showing pretest posttest of affected \&non affected side grip strength CONCLUSION-

The MTWP addresses the range of needs demonstrated by wrist injuries clients, from traditional therapy to prevocational and vocational intervention. The evaluation of the program indicates that the program was successful with wrist injury working age adult. 94\% clients who completed the program returned to work and switched over to different position and different type of work. 56\% clients return to competitive employment with same work type, work situation, having work satisfaction and 80$100 \%$ work skills in compare to premorbid work.

\section{REFERENCES}

1. Yochum T, Rowe L. Essentials of skeletal radiology. $2^{\text {nd }}$ edition Vol. 1.Maryland: Williams \& Wilkins, 1996; 664-665,756-757.

2. Buterbaugh GA, Palmer AK. Fractures and dislocations of the distal radioulnar joint. Hand Clin.1988; 4:361-75

3. Golden GN.Treatment and prognosis of Colles' fracture in a North American Community. American Journal of Public Health 1982; 72:605-7.
4. Gartland JJ Jr, Werley CW. Evaluation of healed Colles'fracture. J Bone Joint surgery [AM] 1951; 33-A: 895-907.

5. Bacorn RW, KurtkzeJF.Colles fracture: a study of two thousand cases from the New York State W o r k mans ' Compe nsation Board. Journal of Bone Joint surgery [AM] 1953; 35-A: 643-58.

6. Golden GN. Treatment and prognosis of Colles' fracture. Lancet 1963; i: 511-5.

7. Katharine Raymond Morey, Anne Harvey Watson. Team approach to treatment of the post traumatic stiff hand: A case report. Physical Therapy; Vol. 66 No.2, February 1986.

8. Wentzensen A, Leutfink D. External quality assurance exemplified by distal radius fracture pilot projects of legal accident insurance. Z Arz tlF ortb ildQ ualitatssich 1997; 91:484-5.

9. Wittemann M, Jung A, Hornung R, Germann G. Die sog. "kle ineH and ve $r$ letzung" und $\mathrm{I} h$ re so $\mathrm{z}$ I o o $\mathrm{k} \mathrm{o} \mathrm{n}$ om ischenFolgen. Chirurg 1994; 65:1004-7.

10. Lyons \& Morse .A Therapeutic Work Program for Head injured clients; AJOT, 1988. 